\title{
LA NOVELA DE PERÓN, NUEVO PERIODISMO Y FICCIONES VERDADERAS
}

\author{
LA NOVELA DE PERÓN, NEW JOURNALISM AND TRUE FICTION
}

\author{
Carlos Basso \\ Universidad de Concepción. Concepción. Chile \\ cbasso@udec.cl
}

\begin{abstract}
Resumen: La Novela de Perón ha sido ampliamente estudiada respecto de las relaciones que presenta en torno a la relación ficción/no ficción, monotema que en general se ha concentrado en su posible vínculo con el llamado "Nuevo Periodismo". Este trabajo explora los inicios de dicha tendencia periodística, que en realidad radican en América Latina, antes que en los Estados Unidos, amplía esa discusión, explica los cuatro elementos que permean de realidad el trabajo ficcional de Martínez, el cual este calificaba dentro de la categoría de "ficciones verdaderas", y concluye que esta novela no puede ser calificada como una obra periodística.
\end{abstract}

Palabras clave: Ficción, no ficción, Nuevo Periodismo, periodismo, Perón.

\begin{abstract}
La Novela de Perón has been widely studied regarding the relationship it presents around the relation between fiction and non fiction, monothema that has generally focused on its possible link with the so-called "New Journalism". This work explores the beginnings of this journalistic tendency, which actually lies in Latin America, rather than in the United States, broadens that discussion and explains the four elements that impregnates Martinez's fictional work, which he qualified within the category of "true fictions", concluding that this book has nothing to do with journalism.
\end{abstract}

Keywords: Fiction, non fiction, New Journalism, journalism, Perón.

Recibido: 10/o9/2018. Aceptado: 14/11/2019. 
$\mathrm{L}$ a mayoría de los estudios relativos a una de las obras más relevantes de la escritura de Tomás Eloy Martínez, La Novela de Perón, gira en torno a la problemática de la ficción y la no ficción que se despliega en sus páginas.

$\mathrm{Al}$ respecto, en distintos trabajos se ha intentado atisbar si es posible clasificar esta novela dentro de la tendencia periodística conocida como Nuevo Periodismo, el cual, a juicio de uno de sus principales exponentes, el periodista Tom Wolfe, nació a mediados de los años 60 en Nueva York. Weingarten (2013) entrega una versión un tanto romantizada respecto del origen de esta tendencia, al señalar que:

Wolfe y muchos de sus contemporáneos reconocieron -algunos antes que la gran mayoría - un hecho destacado en el acontecer de los años sesenta: las herramientas tradicionales con que se realizaban los reportajes resultaban inadecuadas a la hora de cubrir los tremendos cambios culturales y sociales de aquella época. La guerra, los asesinatos, el rock, las drogas, los hippies, los Yippies, Nixon: ¿cómo podía un reportero tradicional, que se ajustaba tan solo a los hechos, proporcionar un orden claro y simétrico a semejante caos? (Weingarten, 2013)

Hay que hacer notar que cuando Weingarten habla de "reportaje" está aludiendo básicamente a un texto de cierta extensión y desarrollado sobre la base de lo que se conoce como "periodismo interpretativo".

Sin embargo, Wolfe sitúa los inicios de la novela de no ficción en razones bastante más pedestres y mucho más egóticas que las anteriores, al señalar que los periodistas que ejercían el periodismo interpretativo consideraban a los diarios como una suerte de peldaño necesario para reunir dinero y experiencia y luego, en algún momento, renunciar al oficio para encerrarse en una cabaña en la cual "trabajar día y noche durante seis meses, e iluminar el cielo con el triunfo final. El triunfo final se solía llamar La Novela" (2012: 13).

En efecto, toda esa camada de grandes periodistas de mediados del siglo XX que se concentraba en los diarios y revistas de Manhattan (como el mismo Wolfe, además de otros como Gay Talese, Jimmy Breslin, Philliph Roth, Norman Mailer y Truman Capote, entre muchos), aspiraba a emular a los grandes escritores estadounidenses, como Hemingway, Fitzgerald o John Dos Passos. 
En ese contexto, Wolfe explica que a inicios de los años '6o, en lo que denomina "las esferas del reportaje", surgió la idea de "hacer posible un periodismo que... se leyera igual que una novela. Igual que una novela, a ver si ustedes me entienden. Era la más sincera fórmula de homenaje a La Novela y a esos gigantes, los novelistas, desde luego" (Wolfe, 2012: 18).

De ese modo, el "Nuevo Periodismo", practicado básicamente en revistas como The New Yorker o Vanity Fair, implicaba escribir sobre hechos no ficticios, pero utilizando para ello herramientas literarias, las que Tom Wolfe denominaba "procedimientos" y que según explicaba son cuatro: la construcción escena por escena, el uso de diálogos, el punto de vista en tercera persona y la descripción de gestos, detalles y hábitos cotidianos (2012).

Con lo anterior y otras técnicas más, se buscaba crear el efecto de verosimilitud de las novelas del siglo XIX e inicios del XX, y su máximo éxito fue $A$ Sangre Fría, de Truman Capote (inicialmente publicado en una serie de cuatro capítulos en The New Yorker), libro que “demostró que la novela de no ficción o novela-reportaje podía conjugar el rigor documental con las exigencias artísticas de la novela realista” (Chillón, 2014).

\section{El origen latinoamericano}

Ahora bien, hay un detalle que Wolfe probablemente ni siquiera sospechó alguna vez: que esa idea tan brillante (y simple) de escribir periodismo en forma literaria había surgido varios años antes de los sesenta en América Latina y que el primer periodista que tuvo la osadía de hacer algo semejante fue Gabriel García Márquez, con Relato de un náufrago, publicada en 1955 como una serie de 14 capítulos en el diario El Espectador de Bogotá (a favor de Wolfe debemos comentar que recién en 1970 se editó como libro), hecho que para Tomás Eloy Martínez es el verdadero punto de inicio del Nuevo Periodismo.

A ello se suma que la primera novela de no ficción propiamente tal publicada como libro fue Operación Masacre (1957), escrita por el periodista argentino Rodolfo Walsh.

No obstante, Tomás Eloy Martínez siempre negó que La Novela de Perón fuera una obra que pudiera ser considerada como periodismo o novela 
de no ficción, ante lo cual aseveraba que lo que había hecho era construir un libro ficticio que parecía periodístico.

De hecho, argumentaba que "invirtió" la técnica del Nuevo Periodismo, escribiendo una novela con una cierta estructura periodística, cuando en realidad lo que resulta evidente es que usó hechos reales (los cuales giran en torno a la matanza de Ezeiza y la vida de Perón desde su nacimiento hasta el momento en que aborda el avión de regreso a Buenos Aires) que adobó con material proveniente de su imaginación, titulándolo con el sustantivo "novela", para indicar su ficcionalidad, asumiendo que para la mayoría de las personas el concepto de "novela" es un indicador inequívoco de un trabajo de ficción.

Al respecto, afirmó que "La novela de Perón no es una fábula de no ficción, ni una contribución herética al nuevo periodismo, sino lisa y llanamente una novela poblada por personajes históricos, muchos de los cuales están todavía vivos" (Martínez, 1988: 42).

Reafirmando lo anterior, aseveró que lo que hizo en La Novela de Perón fue simplemente seguir una tradición literaria argentina, en orden a entremezclar lo imaginario con lo histórico y la ficción con otros discursos (la poesía, la sociología, la filosofía, el periodismo), lo que antes habían hecho autores como Lucio V. Mansilla, Roberto Artl y Jorge Luis Borges.

Pese a ello, si nos atenemos a la definición de González de la Aleja y Barcelona de lo que es el "Nuevo Periodismo", estaríamos dentro de dicha categoría, pues según ellos se trata de "un reportaje periodístico que se pueda leer como novela o viceversa” (1985: 67).

En este caso, además, hay cuatro elementos que coadyuvan a entender que este libro es una suerte de híbrido entre ficción y no ficción que se mueve entre los márgenes de trabajo periodístico. Se trata de el "efecto de contigüidad", el contexto del Nuevo periodismo, del aspecto de verosimilitud del libro y la idea de que lo ficticio puede entregar claridad acerca de hechos reales.

\section{Los cuatro elementos}

Sobre el "efecto de contigüidad" hay que indicar primeramente que el propio Martínez pensaba que el incluir la palabra "novela” en el título era una 
suerte de aviso en orden a que la obra era ficcional, pues pensaba que la simple palabra era "sinónimo de invención” (Martínez, 1988: 41).

Sin embargo, pronto se dio de que estaba equivocado, pues La Novela de Perón se publicó inicialmente como un folletín por entregas en el semanario El Periodista, entre agosto de 1984 y junio de 1985, por lo cual apareció rodeada de artículos sobre hechos no ficticios, los cuales trasuntaban verosimilitud a su texto (Martínez, 2004, p. 8-9).

Además, se dio cuenta de que, aunque la palabra "novela" estuviera en el título, junto a ella había una que era mucho más significativa para los argentinos, que además remitía de inmediato al plano de la realidad: "Perón”.

Tal como señala Girona, ambos términos ("novela" y "Perón”) son contradictorios entre sí y por ello "la declarada asociación de ficción con ese nombre tan consagrado en la Argentina no deja de ser maliciosa" (1995: 45).

Finalmente, Martínez entendió que si se escribe acerca de una figura de la vida real, de alguien de mucha connotación, y quien lo hace es un periodista conocido por escribir relatos periodísticos, entonces la mayoría del público asumirá que aquello que se relata no es ficcional:

Toda escritura es un pacto con el lector. En la escritura periodística, el pacto está determinado por el lugar que ocupa esa escritura: ese lugar es el lugar de la verdad. Quien toma un diario o una revista se dispone a leer la verdad. Lo sorprendería que la información fuera otra cosa. En el caso del periodismo y de la historia, entonces, es el medio, el género, lo que decide que allí está la verdad. (Martínez, 2016).

Y claro, el efecto de contigüidad se acrecienta, dado que Martínez no solo habla sobre Perón, sino acerca de una multiplicidad de otros personajes bien conocidos en Argentina: “Isabelita”, José López Rega, Héctor Cámpora, etc.

A lo anterior habría que agregar un elemento adicional: la palabra "novela" ya no define tan férreamente el que un libro sea una obra necesariamente ficcional. Un buen ejemplo de ello es Una novela criminal, de Jorge Volpi. Como el mismo autor señala en la introducción, lo que escribió es una "novela documental" o "novela sin ficción" (Volpi, 2017), pues el texto se refiere a hechos reales, que no fueron ficcionados por el autor, sino, por 
el contrario, investigados periodísticamente.

El segundo elemento es el relacionado con el contexto del Nuevo Periodismo. Si bien La Novela de Perón apareció en 1985, casi 20 años después de que comenzara el movimiento de dicho nombre en los Estados Unidos, para su fecha de la publicación periodistas como Truman Capote, Norman Mailer o Gay Talese eran celebridades mundiales, y resultaba común que los periodistas que se lanzaran a escribir libros lo hicieran siguiendo los cánones del Nuevo Periodismo. Desde esa perspectiva, entonces, era fácil creer que cualquier libro escrito por un periodista (aunque dijera "novela" en su portada) era un trabajo de no ficción.

A lo anterior se suma, como tercer elemento, el hecho de que el libro tiene un manifiesto aspecto de verosimilitud, que está dado por la gran cantidad de información y la exactitud que posee respecto de los hechos reales, pues no basta con poner nombres de personajes reales en un libro para que dicho texto sea verosímil, sino que es necesario que todo lo que los rodea, incluyendo el ambiente, el lenguaje, los objetos, los lugares y las descripciones, también lo sea.

Es evidente que el autor lo sabía y en el archivo de la Fundación Tomás Eloy Martínez, en Buenos Aires, se resguardan los apuntes mecanografiados que Martínez utilizó durante la escritura del libro. Entre ellos es posible ver, por ejemplo, fichas en las cuales figuran las marcas, modelos y calibres de las armas que se usaron en la masacre de Ezeiza, que no son producto de la imaginación del autor, sino de su trabajo periodístico, en medio del cual recopiló todos esos antecedentes.

Del mismo modo, existen planillas en las que Martínez fue anotando minuto a minuto lo que sucedía a la misma hora en distintas partes del mundo (Madrid, en el avión y en Buenos Aires) y hay otras fichas escritas a máquina en las cuales se describen hasta los más mínimos detalles de las construcciones cercanas a Ezeiza, incluyendo la iglesia del barrio 1 Esteban Echeverría, por ejemplo. Por cierto, la biblioteca de la fundación Tomás Eloy Martínez, en la cual están todos los libros que Martínez poseyó en vida hay decenas, quizá cientos de libros sobre Perón, sobre Evita, sobre peronismo y sobre las dictaduras militares en Argentina, que obviamente utilizó en su reconstrucción de los hechos.

En otras palabras, mientras preparaba esta novela, Martínez hizo el mismo trabajo que efectúa cualquier periodista investigador, que se aper- 
sona en los lugares donde sucedieron o suceden los hechos que investiga, que toma apuntes de todo, que encuentra datos reales que son desconocidos (como el acta de nacimiento de Perón, la cual deja en claro que fue un hijo ilegítimo) y los pone en contexto.

Por ello no resulta extraño que en los "reconocimientos" que figuran al final de La Novela de Perón el autor dejara constancia de sus agradecimientos a hombres y mujeres que menciona con nombre y apellido (como Mabel Preloran, Luis César Perlinger, Julio Lanzarotti y Mercedes Villada Achával de Lonardi), y a otras personas, a las cuales solo califica como "los Siete testigos, que me abrieron sus cajas de papeles y toleraron mis interrogatorios interminables" (Martínez, 2015: 469), sin identificarles, resguardando el secreto de las fuentes, como lo hace cualquier periodista profesional.

Todo lo anterior fue lo que permitió a Martínez elaborar un relato completamente verosímil y creíble para cualquiera que conozca los hechos. No cabe duda de que muchos de quienes leyeron el libro deben haber estado en Ezeiza el día de los hechos y seguramente el relato construido por el autor les debe haber parecido completamente ajustado a los hechos. Si es así, ¿̇por qué no entonces confiar en que todo lo demás es cierto también?

Martínez, es más, se cuidó mucho de no rebasar los límites de la verosimilitud en la novela y las escasas escenas que rayan en lo real maravilloso que hay en ella, y que de algún modo son una clave para que el lector entienda que lo que está leyendo es una fantasía, son tan sutiles que es muy fácil pasarlas por alto.

Una de ellas, por ejemplo, es cuando describe a su alter ego Zamora viajando en auto desde Francia con un tercero, a fin de entrevistar a Perón en España. Aunque en la vida real ese viaje solo tuvo algunas dificultades a consecuencias de una tormenta de nieve, en la ficción Zamora y su acompañante sienten que el viento entra al auto "y se puso a zumbar. No es el viento, son moscas, dijo mi amigo. Aquello se puso insistente. Abrimos las ventanas. Fue peor. Sentimos unos tajitos en el cuello. Tuvimos que detenernos para secar la sangre" (Martínez, 2015: 345).

Luego de que el acompañante de Zamora recitara un conjuro contra el mal de ojo, a ambos se les rompió la pechera de la camisa. Cuando regresaban a Francia, dice Zamora, vieron una lluvia de pájaros y su amigo dijo "Es Perón” (Martínez, 2015: 345). 
Nada de lo anterior llega a internarse derechamente por los meandros de lo real maravilloso al estilo garciamarquiano, ni tampoco por la tradición mágica de la literatura europea, pero son pequeños guiños que ningún lector atento podría pasar por alto.

Un cuarto elemento que es necesario agregar es el que dice relación con el primer epígrafe del libro, una frase extractada de Paris era una fiesta, de Ernest Hemingway: "Si el lector lo prefiere, puede considerar este libro como una obra de ficción. Siempre cabe la posibilidad de que un libro de ficción deje caer alguna luz sobre las cosas que antes fueron narradas como hechos" (Martínez, 2015: 11).

Como señala Girona, La Novela de Perón "desborda los límites de lo puramente imaginario" (1995: 44) y, en dicho sentido, la elección del epígrafe no es una casualidad. Por el contrario, es un aviso hacia el lector, una especie de señal de tránsito que confunde ficción con no ficción y que da a entender que, bajo el manto de la primera, en realidad estamos en el campo de lo segundo.

\section{Ficciones verdaderas}

Así, dando una vuelta de tuerca a todas las definiciones como "Periodismo literario", "Periodismo narrativo", Periodismo de no ficción", "Novela de no ficción", "Novela sin ficción" y otras que se refieren a textos periodísticos, Martínez acuñó su propia definición para explicar qué hacía, consciente sin dudas de lo que Mattos pensaba al respecto, al señalar que pese a todos los estudios críticos que existen respecto del trabajo del periodista argentino, estos "se resisten a encajar en los parámetros de género hasta hoy consagrados. Contienen demasiada ficción para los bordes que definen las novelas históricas, las composiciones biográficas o el llamado nuevo periodismo" (Mattos, C., en Martínez, 2006: 7-8)

A este respecto, el autor explicaba que aunque el periodismo narrativo podía convertir un hecho de la vida real en drama o en comedia, pues "la realidad se estira, se retuerce, pero jamás se convierte en ficción”, de algún modo sucede lo mismo con la historia, aquello que Rancière definía como "una disposición de acciones por la cual no solo ha habido primero esto y luego esto otro, sino también una configuración que une hechos y permite 
presentarlos como un todo: lo que Aristóteles llama un muthos; una trama, un argumento" (2013).

Dejado eso por sentado, aseguraba que dentro de la "reelaboración de lo real" existía una zona distinta, ubicada en las comisuras del periodismo, de la historia y de la ficción:

Hay una categoría que he llamado ficciones verdaderas porque, en ese caso, el gesto de apropiación de la realidad es más evidente y su interdependencia con el imaginario de la comunidad dentro de la cual el texto se produce y con el momento en el cual se produce es, también, mucho más clara. Esta actitud puede no ser deliberada, pero sin duda es inequívoca. (Martínez, 2016)

Desde ese punto de vista, Martínez señala que uno de los ejemplos más claros de ficción verdadera es El reino de este mundo y su famoso prólogo. Aunque allí se usa por primera vez el concepto de lo Real Maravilloso asegura que se trata de una ficción verdadera, sobre todo tomando en consideración que la historia parte a consecuencias de la lectura de Alejo Carpentier de las tres partes que componían la Descripción topográfica, física, civil, política e histórica de la parte francesa de la isla de Santo Domingo, y que el propio autor admitiría después fue la principal fuente documental que utilizó para escribir el libro, a lo cual hay que sumar la famosa visita que hizo a las ruinas de Sans Souci y La Ferriére, en 1943, con lo cual inicia el prólogo de la primera edición.

De acuerdo con Martínez, las ficciones verdaderas básicamente tienen tres estímulos, tres motivos por los cuales ser escritas: llenar un vacío de la realidad, escribir lo omitido o, bien, "rehacer la realidad, reescribirla, transfigurando según las leyes del propio deseo o, como bien señala Borges, del placer" (Martínez, 2016).

Vargas Llosa coincide con dicho planteamiento, al señalar que si bien las novelas mienten, al mismo tiempo, "de una manera menos cruda y explícita, y también menos consciente, todas las novelas rehacen la realidad" (2015).

Así, argumenta que las novelas se escriben para alterar los hechos y contar las historias que los historiadores no pueden relatar, por medio de lo que define como "una curiosa verdad, que solo puede expresarse encubierta, disfrazada de lo que no es" (2015). 
Citando a Valle Inclán, precisa que "las cosas no son como las vemos sino como las recordamos" (2015) y, sin dudas, esa es una reflexión que Martínez tenía tremendamente presente, al punto que fue su motor real al momento de gestar La Novela de Perón:

Mi idea inicial, al escribir el libro, es que Perón, a quien yo entrevisté, me hizo vehículo de la construcción de un monumento histórico que yo sé que es falso. Entonces, con las herramientas que he reunido para completar ese monumento histórico, voy a tratar de demostrarle a los argentinos que durante más de cuarenta años en aquel momento, a la salida de la novela, vivieron a la sombra de Perón y de su ideología -y aún ahora, porque aunque su ideología esté transformada, el peronismo continúa-, como un acto de justicia, una imagen de Perón que correspondiese con la imagen verdadera. (Neyret, 2002)

Lo anterior se compadece con una idea muy semejante, que Javier Cercas estampó en el prólogo de su novela de no ficción El impostor: "para llegar a la verdad, hay que mentir" (2014), lo que Martínez buscó valiéndose para ello de una trama que funde varias líneas narrativas centrales (el viaje de Perón desde España a Argentina, la vida de Perón hasta el exilio, la actuación del periodista Zamora y los sucesos de Ezeiza) y que termina convenciendo acerca de su verosimilitud.

Sin embargo, nada de ello tiene que ver, realmente, con el Nuevo periodismo o con el periodismo en general. El que Martínez haya utilizado en su novela los "procedimientos" detallados por Wolfe no indica ninguna cercanía con el periodismo. De hecho, hay que recordar que esos "procedimientos" no son más que estilos tomados de la literatura y adoptados por el periodismo.

Las razones antes descritas como motivos por los cuales se tendía a pensar que La Novela de Perón pudiera ser un texto de no ficción no son suficientes tampoco. Es cierto que los elementos antes enumerados (el "efecto de contigüidad", el contexto que brindaba el Nuevo periodismo, la verosimilitud lograda en el libro gracias al uso de las técnicas de investigación propias del periodismo y la idea de que lo ficticio es una vía de llegada a lo real) contribuyen a pensar en ello, pero tampoco son indicativas de un libro periodístico, pues en términos estrictos, el que un texto sea periodístico se 
define desde 1690 al menos por los preceptos establecidos por Tobías Peucer en su tesis doctoral.

En ella, Peucer citaba a Luciano de Samosata y señalaba que el fundamento esencial de lo que hoy conocemos como periodismo es que quienes los escribían debían respetar y buscar la verdad, lo que complementaba con los pensamientos de Cicerón al respecto, quien señalaba en Sobre el orador, libro Segundo, que "la primera ley de la historia es no atreverse a decir nada falso y, luego, atreverse a decir cuanto sea verdadero, y que no haya sospecha ni de favor ni de enemistad cuando se escribe" (Sierra de Cózar, 1996, p. 44).

El Nuevo periodismo violó algunas normas sacrosantas de periodismo moderno, como las establecidas a partir de la aparición del telégrafo, en orden a que las noticias debían ser concisas y exentas de detalles y opiniones (Scanlan, 2003), y también se internó por terrenos desconocidos, al dejar de lado la estructura redaccional estándar del periodismo, la pirámide invertida, pero ninguno de los grandes autores de la época dorada del Nuevo periodismo, desde García Márquez a Norman Mailer o Truman Capote, osó violar el principio que indica que no se puede escribir algo que sea falso, lo que forma parte importante de La Novela de Perón, a tal punto que en las escenas finales José López Rega masculla milésimas de segundos antes las palabras que luego salen de la boca de este, como si se hubieran fundido en un solo ser (en el López Rega era quien detentaba la voluntad).

Ciertamente, Martínez sabía muy bien lo que hacía. Si su proyecto acerca de Perón se hubiera limitado a lo comprobable, a la evidencia demostrable, no habría tenido ni remotamente el impacto que su libro consiguió ni, muchos menos, habría cumplido el objetivo confeso que se trazó en orden a reescribir la historia y usar la ficción con el fin de dar una versión veraz de lo que Perón había sido.

\section{Referencias}

Caprara, S. (2007). "Derribando fronteras". Tram(p)as de la Comunicación y Cultura, Universidad Nacional de la Plata, No 56, pp. 32-35.

Cercas, Javier. (2014). El impostor. Recuperado de https://www.amazon. com/El-impostor-Spanish-Javier-Cercas-ebook/dp/BooOQSW3PC/re 
$\mathrm{f}=\mathrm{sr} \_1 \_1$ ?crid=3GNCX967EJFXA\&keywords $=$ el+impostor + javier + ce rcas\&qid $=1573313153 \&$ sprefix $=$ el+impostor + cercas\%2Caps\%2C258\& $\mathrm{sr}=8-1$, revisado el o6 de noviembre de 2019.

Chillón, A. (2014). La palabra facticia. Literatura, periodismo y comunicación. Recuperado de https://www.amazon.com/palabra-facticiaLiteratura-periodismo-comunicación-ebook/dp/BooUN3HQSI/ref=s r_1_1?keywords $=$ La + palabra + facticia. + Literatura $\% 2 \mathrm{C}+$ periodismo $+\mathrm{y}$ +comunicación\&qid $=1573177921 \& s r=8-1$, revisado el 07 de noviembre de 2017.

Girona, N. (1995). Escrituras de la historia. La novela argentina de los años 80. Cuadernos de Filosofía, anejo XVII, Departamento de Filología hispánica, Universidad de Valencia, 176 p.

González de la Aleja, M., y Barcelona, M. (1985). "Nuevo periodismo, las mentiras de Truman Capote, y otras historias". Atlantis, Vol. 7, № 1-2, pp. 67-78.

Guzmán, M., Royo M. (2001). "El tejido del discurso 'no ficcional' en la escritura de Tomás E. Martínez". Cuadernos de la Facultad de Humanidades y Ciencias Sociales, Universidad Nacional de Jujuy. 2001, pp. 149-157.

Junieles, John (2006). "La novela de Perón, de Tomás Eloy Martínez: Memorias de la patria perdida”. Espéculo, recuperado de https://pendientedemigracion.ucm.es/info/especulo/numero32/novperon.html, revisado el 25 de enero de 2017.

Martínez, T. E. (1988). "Ficción e historia en La novela de Perón”. Hispamérica, Año 17, Nº49, pp. 41-49.

. Martínez, T. E. (1996). Las memorias del general, $1^{\text {a }}$ edic., 218 p. Argentina, Buenos Aires: Planeta.

. (2004). "Ficción, historia, periodismo: límites y márgenes". $R e$ vista Telar, Instituto Interdisciplinario de Estudios Latinoamericanos IIELA, Facultad de Filosofía y Letras. Universidad Nacional de Tucumán, N.1, p. 7-16.

. (2006). La otra realidad. Antología /Tomás Eloy Martínez, con prólogo de Cristine Mattos. 1ra ed., 427 p. Buenos Aires: Fondo de cultura económica.

- Martínez, T. E. (2009). Las vidas del general, Memorias del exilio y otros textos sobre Juan Domingo Perón. Recuperado de 
https://www.amazon.com/Las-vidas-del-General-Spanish-ebook/dp/ B018F298DO/ref=sr_1_1?keywords=Las+vidas+del+general+tomas+ eloy+martinez\&qid=1573303051\&sr=8-1, revisado el 06 de noviembre de 2019.

(2015). La novela de Perón, Ed. conmemorativa., 488 p. Buenos Aires: Alfaguara.

.(2016). Ficcionesverdaderas. Recuperadodehttps://www.amazon.com/Ficciones-verdaderas-Spanish-Tomás-Mart\%C3\%ADnezebook/dp/Bo19D1YOKS/ref=sr_1_1?keywords=ficciones+verdaderas \&qid=1573178001\&sr=8-1, revisado el 07 de noviembre de 2019.

Neyret, J. (2002). "Novela significa licencia para mentir". Espéculo. Revista electrónica de estudios literarios. Universidad Complutense de Madrid, recuperado de https://pendientedemigracion.ucm.es/info/especulo/numero22/t_eloy.html, revisado el 19 de enero de 2017.

Rancière, Jacques (2013). Figuras de la historia. Recuperado de https:// www.amazon.com/Figuras-historia-Spanish-Jacques-Rancière-ebook/ dp/BooG5JPTLU/ref=sr_1_1?keywords=Rancière\%2C+Jacques+Fig uras+de+la+historia.\&qid $=1573177796 \&$ sr $=8-1$, revisado el o7 de noviembre de 2019.

Rosano, Susana (2006). "En definitiva, en Argentina todos caemos en el barroco fúnebre. Reportaje a Tomás Eloy Martínez”. Revista Iberoamericana, Vol. LXXII, Números 215-16, pp. 657-662.

Scanlan, C. (2003), "Birth of the inverted pyramid: A child of technology, commerce and history". Poynter.org, Recuperado de https://www. poynter.org/news/birth-inverted-pyramid-child-technology-commerce-and-history, revisado el o8 de noviembre de 2019.

Sierra de Cózar, A. (1996). "Traducción castellana y notas”. Estudios sobre el mensaje Periodístico, $\mathrm{N}^{\circ} 3$, pp. 37-53.

Vargas Llosa, M. (2015). La verdad de las mentiras. Recuperado de https://www.amazon.com/verdad-mentiras-Truth-about-Spanish/ $\mathrm{dp} / 8490626103 / \mathrm{ref}=\mathrm{sr} \_1 \_1$ ? keywords=la+verdad+de+las+mentiras\& qid $=1573179986 \& s r=8-1$, revisado el o7 de noviembre de 2019.

Volpi, Jorge. (2017). Una novela criminal. Recuperado de https://www. amazon.com/s?k=una+novela + criminal + jorge + volpi\&crid $=26 \mathrm{I}_{3} \mathrm{Z}_{3} \mathrm{~L}$ VZPUSR\&sprefix $=$ una + novela + criminal\%2Caps\%2C $313 \&$ ref $=$ nb_sb_ ss_i_1_19, revisado el o7 de noviembre de 2019. 
Weingarten, M. (2013). La banda que escribía torcido. Recuperado de https://www.amazon.com/banda-que-escrib\%C3\%ADa-torcido/ $\mathrm{dp} / 8494034871 / \mathrm{ref}=\mathrm{sr} \_1 \_1$ ?keywords=Weingarten+La+banda+que+ escrib\%C3\%ADa+torcido.\&qid=157317786o\&sr=8-1, revisado el o7 de noviembre de 2019.

Wolfe, Tom (2012). El nuevo periodismo, $2^{\mathrm{da}}$ edic., 214 pp. Barcelona: Anagrama. 